\title{
Uma proposta para representar graficamente tomadas de decisão éticas
}

\author{
Luiz Paulo Carvalho $^{1}$, Jonice Oliveira ${ }^{1}$, Flávia Maria Santoro ${ }^{2}$ \\ ${ }^{1}$ Programa de Pós-Graduação em Informática (PPGI) - UFRJ \\ Rio de Janeiro, RJ - Brasil \\ ${ }^{2}$ Departamento de Ciência da Computação (DCC) - UERJ \\ Rio de Janeiro, RJ - Brasil \\ luiz.paulo.carvalho@ppgi.ufrj.br, joniceddcc.ufrj.br, \\ flavia@ime.uerj.br
}

\begin{abstract}
The course of action through which agents reach their decisionmaking processes, ethical or unethical, can be formalized through Ethical Decision-Making Models (EDMMs). The interest in ethical decision-making both from academia and practitioners in Business Informatics has increased recently due to the advances in the Artificial Intelligence field. Research is focused on theoretical models to explain ethical decision-making, factors that influence it and measuring tools to assess it. However, to the best of our knowledge there is an absence of a graphic resource to represent the elements of an EDMM that goes beyond the textual scope. This paper is the first step in thinking-making a graphical representation that includes elements of EDMM, enables a more complete information panorama as possible, documents ethical decision-making and facilitates the visualization of these knowledge assets.
\end{abstract}

Resumo. O processo pelo qual os agentes chegam aos seus processos de tomada de decisão, éticos ou antiéticos, pode ser formalizado por meio de Modelos de Tomada de Decisão Ética (MTDE). O interesse pela tomada de decisão ética, tanto da academia quanto dos profissionais de Informática Organizacional, aumentou recentemente devido aos avanços no campo da Inteligência Artificial. A pesquisa está focada em modelos teóricos para explicar a tomada de decisão ética, fatores que a influenciam e ferramentas de medição para avaliála. Até onde sabemos, não há recurso gráfico para representar os elementos de um MTDE que extrapole o âmbito textual. Este trabalho é o primeiro passo para se pensar em uma representação gráfica que inclua elementos de MTDE, possibilite um panorama de informações mais completo possível, documente a tomada de decisão ética e facilite a visualização desses ativos de conhecimento.

\section{Introdução e gatinhos, pois todo mundo ama gatinhos}

Qual é a relação entre Ética, adoção de gatos e Redes Sociais Online (RSO)? Para expor como a computação é onipresente, difundida e prevalece culturalmente, iniciamos este trabalho analisando essa questão. [Rulli 2017] debate eticamente a relação entre comprar 
ou adotar animais, defendendo a adoção e debatendo a moralidade de ambas as opções. Há indícios de que cada vez menos gatos pretos estão sendo adotados porque, basicamente, eles são menos esteticamente agradáveis nas fotos [Barton 2018]. Gatos pretos não são "self-friendly". À medida que avança a cibercultura de exposição da vida e validação estética por terceiros, a motivação de cuidar de animais domésticos que favoreçam a construção de experiências e imagens agradáveis é proporcional. Por que adotar um gato preto que estraga minhas fotos se também posso escolher um mais claro de graça? Se o peso da responsabilidade por mantê-lo é/ou será meu, por que devo escolher um animal que é prejudicial ao prazer de minhas experiências contemporâneas?

Neste ponto, você deve estar se perguntando o que isso tem a ver com Informática? Desenvolvido e de propriedade do Facebook, Instagram ${ }^{1}$ é uma RSO dedicada principalmente ao compartilhamento de imagens ou fotos, utilizada mundialmente por centenas de milhões de usuários, com alcance planetário e números crescentes [Kemp 2020]. Em sua versão atual, 10.34.0, o Instagram tem um limite máximo de tamanho de arquivo e resolução de qualidade de suas imagens [Webb 2021]. Ou seja, a aplicação será capaz de "manipular" as características das imagens inseridas na plataforma para adequá-la a parâmetros específicos. Entretanto, essa prática é opaca para a maioria dos usuários.

Desde sua invenção, a fotografia não foi projetada para representar elementos de cores escuras. Consequentemente, a concepção tecnológica não abarcou a população negra [Lewis 2019]. Muitas décadas de avanço tecnológico nessa área negligenciaram essa característica, da qual surgiram o cinema, as câmeras de vigilância e as câmeras dos smartphones. Hoje, o racismo algorítmico em relação aos aplicativos de reconhecimento facial é discutido [Silva 2020], promovendo discriminação e opressão por meio de tecnologias de captura de imagem excludentes ou desatualizadas combinadas com um falso discurso de "eficácia" [Buolamwini e Gebru 2018].

Quem também é afetado? Gatinhos pretos. E os prejudicados? Organizações de cuidado e proteção animal, que acumulam gatos pretos ou recebem cada vez mais gatos pretos abandonados por não serem "self-friendly" ou são prejudicados por algum aspecto negativo da cibercultura, já que a renderização das imagens que os contêm é dificultada por sua própria cor. Apesar disso, os gatinhos pretos são alheios à moral ou à ética em torno de suas condições, muito diferente da população negra. Quem é ou é responsável pela rejeição dos gatos pretos? Qual é a decisão ética a ser tomada pelas organizações de proteção e cuidado animal? Quem pode ou deve resolver ou mitigar esse problema?

Há alguns anos, esse era um problema inexistente para as organizações de proteção e cuidado animal. $\mathrm{O}$ ciberespaço se expandiu e indiretamente englobou atores que foram catapultados a interagir com o domínio computacional. Ética é um recurso para esses contextos. Atores que antes permaneciam na fronteira ou fora das influências concretas do digital em rede são arrastados para o ciberespaço, voluntariamente ou não. Gatinhos pretos ocupam espaço e recursos em abrigos; os abrigos deveriam rejeitá-los e preservar seu espaço e recursos para outros gatos "mais interessantes para a cibercultura"? As entidades governamentais devem realizar campanhas de conscientização sobre este tema? $\mathrm{O}$ Instagram deve estar socialmente e tecnologicamente engajado nessa questão? Os adotantes deveriam pensar em adotar animais não como um meio para seu prazer e vaidade

\footnotetext{
${ }^{1}$ https://www.instagram.com/. Disponível em 05/05/2021
} 
digital e sim como um fim para o bem-estar do animal? Seguindo raciocínio análogo ao segundo imperativo categórico de Kant [Fieser 2020]. Qual é a decisão ética a tomar?

O curso de ação pelo qual chegamos aos processos de tomada de decisão, éticos ou antiéticos, pode ser formalizado por meio de Modelos de Tomada de Decisão Ética (Ethical Decision-Making Models - EDMMs) [Torres 1998]. As últimas quatro décadas mostraram um interesse crescente na tomada de decisões éticas, acadêmica ou profissional [Luca Casali e Perano 2020]. A pesquisa se concentra em modelos teóricos para explicar a tomada de decisão ética, fatores que a influenciam e ferramentas de medição para avaliá-la. Várias estruturas conceituais datam do século 20, genéricas ou orientadas para um domínio, como Marketing e Vendas. Em Sistemas de Informação, dois dos mais prestigiosos livros da área propõem EDMMs, [Stair e Reynolds 2018, p. 622] e [Laudon e Laudon 2020, p. 129]. Entretanto, são generalistas e flexíveis em domínio, semelhantes a outros EDMMs bem estabelecidos [Torres 1998]. Embora a análise exponha uma desconexão computacional, a intenção é válida.

Até onde sabemos, não há recurso gráfico para representar graficamente EDMMs, extrapolando a dimensão textual. A intenção de um EDMM é estruturar e orientar as partes interessadas na tomada de decisão ética, não necessariamente gerenciando o conhecimento de forma eficaz, ou seja, sem registro ou documentação. Algumas propostas recomendam apenas registro por escrito. Para a Gestão do Conhecimento, o conhecimento explícito (escrito) é considerado um avanço em relação ao conhecimento tácito (mentalização ou verbalização) [Nonaka et al. 2018]. Porém, representações gráficas são mais adequadas para cenários com diferentes dimensões e informações simultâneas [von Engelhardt et al. 1996], como pode ser visto nos componentes dos EDMMs. Consolidadas como notações construídas a partir de um design rationale e de epistemologias fundamentadas, estes modelos podem ser interpretados e executados por computadores.

Infelizmente, não resolvemos o cenário ruim que aflige os gatinhos pretos, pelo menos não diretamente. Esta proposta é o primeiro passo para se pensar-fazer uma representação gráfica que inclua elementos de EDMM, possibilite um panorama de informações mais completo possível, documenta a tomada de decisão ética e facilita a visualização desses ativos de conhecimento. Com base na metodologia Design Science Research (DSR) [Wieringa 2014] esta pesquisa pragmática pretende desenvolver um artefato, uma representação gráfica, com embasamento científico e rigor epistemológico.

Gostaríamos de adicionar fotos de gatinhos na Seção 2, mas por causa da restrição de espaço nos limitaremos à fundamentação teórica; na Seção 3, trabalho relacionado; Seção 4, a proposta de pesquisa e; A seção 5 conclui.

\section{2. Ética Computacional e Representações Gráficas}

"Ética é o processo formal de análise intencional e crítica, com clareza e consistência, base para os julgamentos morais de interessados" [Glover 2017], o sujeito da análise Ética é a Moralidade [Fieser 2020]. Mesmo irracionalmente ou inconscientemente, todos nós nos engajamos em tomadas de decisões constantemente; na maior parte, questões ou dilemas éticos pouco ou nada relevantes. Ou seja, estruturar, formalizar e registrar a tomada de decisão ética é, em si, uma atividade que requer tempo e recursos. Por exemplo, ir atrás do perfil online de alguém para comunicar algo crítico e urgente não é um dilema ético se isolado neste contexto; no entanto, se essa pessoa bloqueou você e já deixou claro que 
não deseja interagir com você, é um dilema ético.

Nem todas as decisões precisam de um exame minucioso a ponto de serem analisadas formalmente por um EDMM. Organizações e empresas, públicas ou privadas, muitas vezes se envolvem em tomadas de decisão que envolverão simbólica ou concretamente um número expressivo ou descontrolado de pessoas. Nesse caso, orientar-se racional e conscientemente por meio de um EDMM é um curso de ação recomendado. [Simon 1979], desde a década de 1970, analisou os benefícios das Teorias da Decisão e de uma tomada de decisão racional, buscou compreender e explicar fenômenos que são intrinsecamente interessantes e oferecem aconselhamento direto aos tomadores de decisão em âmbito geral. Por exemplo, quando o Facebook bloqueia uma pessoa qualquer por um discurso de ódio explícito ou quando o Facebook bloqueia Donald Trump [Fung 2021]. A magnitude das duas ações é diferente, assim como as consequências.

Um questionamento metaético sobre os limites de uma ética aplicada à computação e qualquer outra estrutura ética plausível é apropriado. É ético limitar a ética computacional aos aspectos técnicos, desconsiderando suas aplicações, influências e usos? Neste trabalho consideraremos que não é, e estenderemos a ética computacional à qualquer contexto no qual um elemento técnico (Software, Hardware, Rede, Armazenamento de Dados [Stair e Reynolds 2018]) esteja envolvido. Se os pobres gatinhos pretos passam a ser rejeitados e se estima que haja uma forte influência dos fatores computacionais nesse fenômeno, seria inválido desconsiderar isso como uma questão pertinente à ética computacional. Ou, se aplicável, uma ética de SI. Embora a tomada de decisão ética seja um fenômeno multifacetado; a literatura muitas vezes ignora sua natureza heterogênea de uma perspectiva empírica [Luca Casali e Perano 2020]. Analisando a partir de uma perspectiva pós-estruturalista, esse dilema pode estar associado a vários domínios além do computacional. Em vez de uma análise linear, determinística e binária, há uma rede ou rizoma [Escobar 2018], enriquecendo a percepção da realidade.

Não há consenso se o domínio da computação oferece questões ou dilemas éticos únicos ou novos [Johnson 2008], ou seja, há uma especialização na análise e avaliação de fenômenos computacionais, ou eles são universalmente generalizáveis? Como tecnologia, a computação oferece cenários éticos específicos? Acreditamos que sim e seguimos esse raciocínio, por exemplo, leis e regulamentos como o Regulamento Geral sobre a Proteção de Dados (General Data Protection Regulation), na União Europeia, e a Lei Geral de Proteção de Dados Pessoais, no Brasil, existiriam desconsiderando a influência computacional? Vamos mais longe, antes desses artefatos legais, a proteção de dados era uma questão ética menos relevante e problemática em informática organizacional. Hoje, embora os princípios de proteção de dados estejam na literatura há muitos anos, esperase que na década de 2020 essa preocupação ética alcance cada vez mais concretude e materialidade. As empresas de médio ou grande porte são as mais afetadas não só pelos prejuízos financeiros, por conta da multa, mas também pelo impacto negativo em sua imagem, valores e lucratividade [Bioni 2019]. Em países sob influência de leis específicas de proteção de dados, o processamento de dados pessoais de seus funcionários, clientes e parceiros pode burlar a lei? Eticamente, como tomar decisões em casos incomuns?

Ao propor um EDMM à Medicina, [Glover 2017] apresenta um cenário hipotético. MT, um jovem de 16 anos, é diagnosticado com um tumor fatal no cérebro. Seus pais decidem que ninguém deve divulgar a MT sobre sua condição, apesar de ele acessar 
um portal de pacientes que ele e seus pais assinaram há muito tempo. Ele descobre seu diagnóstico por meio de uma pesquisa online e recebe um prognóstico ruim. Ocorrem duas interseções com a computação: (i) em geral, as pessoas encontram prognósticos ruins e enganosos em diferentes ambientes do ciberespaço; (ii) em informática organizacional, o acesso ao portal do paciente, previamente em acordo com seus pais e neste cenário considerado por eles impróprio. Mesmo sendo uma comunicação relacionada à saúde, o dilema ético está principalmente relacionado ao acesso a dados e autodeterminação informativa, para demonstrar como os tópicos que envolvem aplicações computacionais permeiam domínios e áreas sociais. "Direitos e deveres informacionais" é enquadrado como uma das dimensões morais de SI da Era da Informação [Laudon e Laudon 2020].

A Figura 1 mostra um EDMM proposto por Santoro e Costa [Santoro e Costa 2020], modelado usando BPMN (Business Process Model and Notation) ${ }^{2}$. Como em [Stair e Reynolds 2018] e [Laudon e Laudon 2020], a proposta é generalista e flexível em termos de domínio. Nós inserimos dados complementares para enriquecer esta nova versão, (i) rotular os eventos iniciais e finais; (ii) adição de "fatos sobre questões semelhantes" à primeira atividade para envolver fatos sobre o caso específico e outros semelhantes para comparação e análise; (iii) adição de uma tarefa e dado de saída relacionados à documentação, registrando o ativo de conhecimento, ao invés de apenas publicá-lo.

Jones [Jones 1991] propõe um EDMM incluindo o construto "intensidade moral" e sintetizando outros modelos bem estabelecidos. O EDMM de Jones ilustra uma instância de um modelo apresentando design rationale, epistemologicamente construído com base em instâncias anteriores e fator de impacto academicamente alto ${ }^{3}$, apesar de datado à trinta anos atrás.

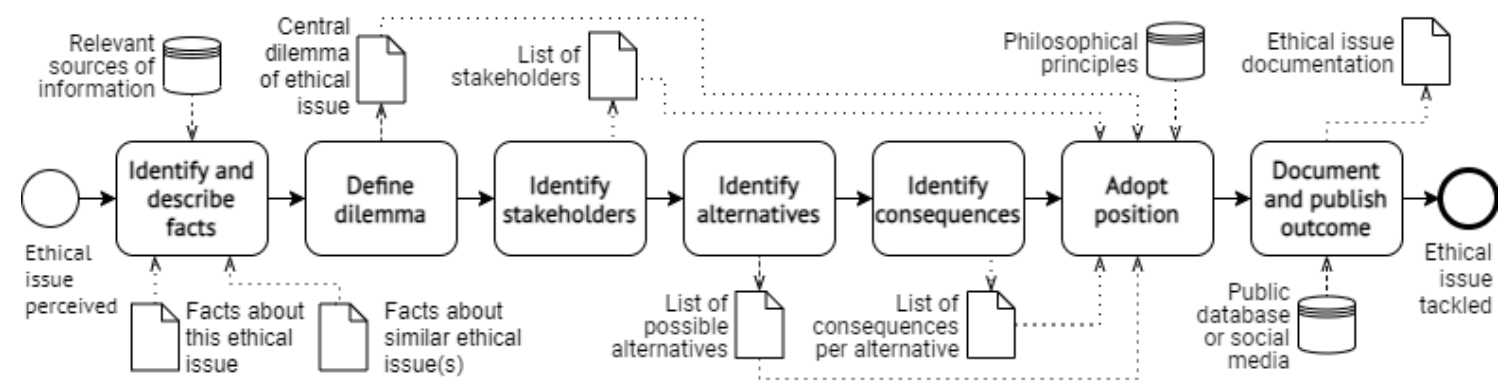

Figura 1. Um processo de deliberação ética (adaptado de [Santoro e Costa 2020])

Em comum, esses modelos apresentam representações gráficas e racionalidade de design com bases epistemológicas referenciadas. Outros modelos estão disponíveis e são encontrados na literatura; escolhemos esses dois exemplos bem fundamentados e com base em fontes reconhecidas. No entanto, a padronização dos produtos de conhecimento gerados por meio desses modelos está ausente. Eles podem ser textos, gravações, rabiscos, mapas mentais rabiscados ou dados informais. As representações gráficas têm várias vantagens sobre o texto [Tversky 2001] [von Engelhardt et al. 1996]. Nas representações

\footnotetext{
${ }^{2}$ https://www.omg.org/bpmn/ . Disponível em 05/05/2021

${ }^{3}$ https://cutt.ly/Pzi2f3P. Disponível em 05/05/2021
} 
gráficas, as estruturas sintáticas envolvem várias dimensões e aspectos, enquanto as estruturas textuais envolvem apenas uma dimensão e aspecto, sequenciados linearmente [von Engelhardt et al. 1996].

Linguagens e notações são tecnologias [Dascal 2002] com o objetivo de informar e operacionalizar a gestão do conhecimento, como representar, registrar, transmitir informações procedimentais [Nonaka et al. 2018], sendo meios comunicacionais. Os modelos são utilizados para representar uma realidade pretendida com a respectiva finalidade, nesta pesquisa, eles são os elementos que compõem a tomada de decisão ética.

\section{Trabalhos relacionados}

EDMMs são uma parte crítica da Ética. Uma questão crucial sobre tais modelos é a suposição de uma área da Ética Normativa. Por exemplo, os especialistas em ética da virtude se concentram nas características das pessoas éticas como a causa primária da tomada de decisão, mas também consideram as consequências ou razões por trás da decisão. Ainda assim, um consequencialista se concentraria nos resultados das decisões. Diferentes modelos de tomada de decisão ética têm sido propostos associados às influências e implicações potenciais da Informática na sociedade. [Jones 1991] revisou os modelos clássicos oferecidos na época e, mais recentemente, outros pesquisadores analisaram modelos bem conhecidos [Cottone e Claus 2000]; [Whittier et al. 2006] [Luca Casali e Perano 2020].

Alguns modelos bem conhecidos são complementados com princípios ou sugestões às etapas. Por exemplo, o modelo de tomada de decisão PLUS, desenvolvido pela Ethics and Compliance Initiative (ECI), aplica filtros éticos para determinar se os componentes éticos da decisão foram abordados: $\mathrm{P}=$ Consistente com as Políticas, procedimentos e diretrizes da minha organização?; L = Aceitável sob as Leis e regulamentos aplicáveis?; U = Está de acordo com os princípios ou valores Universais que minha organização adota?; $\mathrm{S}$ = Satisfaz minha definição pessoal e particular (Self) de certo, bom e justo? Esses filtros suportam algumas das etapas propostas para o processo de tomada de decisão. Etapa 1, definir o problema; Etapa 2, identificar soluções alternativas disponíveis para a questão; Etapa 3, avaliar as alternativas identificadas; Etapa 4, tomar decisão; Etapa 5, implementar decisão; Etapa 6, avaliar decisão. [Baker e Martinson 2001] propuseram o modelo TARES, que representa cinco princípios embutidos: Veracidade, Autenticidade, Respeito, Equidade e Responsabilidade Social. Esses princípios juntos devem orientar as ações do processo de tomada de decisão.

Embora os modelos propostos tenham muito em comum, observamos que nenhum deles fornece suporte gráfico para representar os elementos de um EDMM. Um exemplo genérico de notação gráfica para processos de tomada de decisão é a Decision Model and Notation (DMN). DMN é uma notação para modelagem de decisões e fornece, de acordo com suas especificações ${ }^{4}$ : “[...] um modelo de decisão completo que complementa um modelo de processo de negócio especificando detalhadamente a tomada de decisão realizada em tarefas em processo". Ou seja, sua base e lógica estão subordinadas à modelagem de processos, em especial à BPMN.

Uma boa prática na engenharia de linguagem e notações gráficas é reutilizar, importar ou herdar elementos de outros bem-estabelecidos, porém, desconsideramos DMN

\footnotetext{
${ }^{4}$ https://www.omg.org/dmn/. Disponível em 05/05/2021
} 
como fonte para nosso artefato por três razões principais, (i) sua forte associação com BPMN enfraquece sua independência para outros fins que não a representação de processos de negócios, a tomada de decisão ética é, no entanto, um processo, porém seu baixo grau de repetibilidade, estruturação flexível e incompatibilidade com a ideologia do "negócio" tornam a associação limitada; (ii) consideramos que os elementos do DMN, embora não explicados desta forma nas especificações, complementam as funcionalidades e metadados do BPMN e outras notações dos processos de negócio, ou seja, nenhum é suficiente semanticamente; (iii) a notação é definida por seus proprietários como descomplicada e direta, consideramos que uma notação que envolve escrutínio ético merece seus próprios construtos gráficos e conceituais, ou seja, complementar o DMN com uma extensão relacionada à ética prejudicaria sua essência e, desta forma, nossa proposta.

\section{Uma representação gráfica para EDMMs}

Ao nosso conhecimento, não há notações ou representações gráficas dedicadas à tomada de decisão, exceto DMN, especialmente se dedicado à Ética e aos princípios éticos.

Deve-se notar que duas categorias de metanálise predominam no domínio da tomada de decisão, descritiva e normativa. Os modelos descritivos estruturam e formalizam informações do período passado ou presente, analisando como as entidades tomaram ou tomam decisões a priori, por exemplo, influências e motivações que levam um governo federal a fornecer um aplicativo de sistema de recomendação de saúde durante uma pandemia que aponta tratamentos totalmente ineficazes como possível saída [Tagiaroli 2021]. Modelos normativos estruturam e formalizam informações futuras, recomendando como as entidades podem ou devem tomar decisões a posteriori, por exemplo, considerado como uma opção viável, como um sistema de recomendação de saúde deve operar durante uma pandemia e quais recursos e resultados devem aparecer.

Primeiramente, estipulamos as características contextuais da proposta nos próximos parágrafos, seguidas de exemplos.

A notação deve suportar situações fracamente repetíveis e padronizadas, a intenção é analisar e avaliar casos sem gerar automação ou procedimento repetitivo. A principal intenção do BPMN e do DMN é a repetibilidade, distante da nossa. Exemplo: uma organização inicia uma iniciativa de sustentabilidade social ao estabelecer ações afirmativas que priorizam a contratação de identidades socialmente minoritárias para o setor de Informática; isso não significa que os processos de seleção de todas as unidades de negócios desenvolverão para sempre um novo modelo para cada processo de seleção futuro. Existe um meio-termo entre relativismo radical e padronização imutável.

A notação deve ser usada para dilemas éticos complexos ou abertos. Construir um modelo para cenários simples ou binários é um uso excessivo de representações gráficas. Exemplo: para comunicação com usuários, o formulário de cadastro no aplicativo deve solicitar e-mail; a análise ética desse cenário é simples para necessitar de um modelo gráfico específico de tomada de decisão ética. Visto que a complexidade é inerente às especificidades do contexto, esta característica é subjetiva e fluída.

A notação não deve envolver cenários morais óbvios. Exemplo: John invadiu a RSO privada de Jane e compartilhou o conteúdo íntimo dela na intranet da empresa, concerne a análise da demissão de John da empresa. Basicamente autoexplicativo. Na 
verdade, John é um daqueles que abandonam os gatinhos pretos porque a nitidez de suas imagens no Instagram é mais importante do que o bem-estar animal.

A notação deve apresentar elementos gráficos semanticamente parcimoniosos, uma vez que os elementos gráficos podem ser semanticamente perversos [Moody 2009]. A intenção é zelar pela simplicidade e a intuitividade do aprendizado sem treinamento prévio. Exemplo: usar o ícone do relógio para indicar a ideia de "tempo".

A notação deve priorizar a economia gráfica, o menor número possível de símbolos notacionais que englobem todos os significados possíveis [Moody 2009], sem ambiguidade. Exemplo: BPMN possui mais de cem elementos gráficos individuais; suas combinações somam mais de mil possibilidades [Genon et al. 2011], excessivamente complexas se utilizadas com todo o seu potencial semântico.

A notação deve abranger princípios éticos específicos e elementos que os representem graficamente, e acreditamos que este seja o desafio-chave e mais trabalhoso. Este item especializa a notação proposta como relacionada à Ética, independentemente do domínio e configuração. Os EDMMs são diferentes dos modelos genéricos de tomada de decisão, necessariamente por causa da entrada de constructos e princípios éticos em suas estruturas. Isso se considerarmos que nem todos os princípios éticos podem ser reduzidos a ícones gráficos. Exemplo: como representar graficamente os elementos da Ética Utilitarista? Virtuosa? Kantiana? Ética do Cuidado? Ética da Resistência? [Fieser 2020]

A notação deve considerar a realidade concreta e material, iremos detalhar ilustrando. Por exemplo: a partir do iPhone 12, a Apple não comercializará mais seus smartphones em conjunto com carregador e fones de ouvido. Essa foi uma decisão ética justificada pela empresa visando a sustentabilidade natural e a redução da geração de lixo eletrônico. Os especialistas são céticos quanto ao altruísmo ambiental, semelhante ao fenômeno de green washing. Entre as opções que a empresa poderia seguir, a de possibilitar o reuso, a manutenção, o reparo e o combate à obsolescência programada era a mais indicadas; mesmo assim escolheu outro caminho. O argumento de que embalagens menores e menor produção de componentes eletrônicos são positivos para o meio ambiente, mas como seus clientes vão carregar seus celulares... sem carregadores? [Calma 2020]. E se o objetivo é "produzir menos", há novamente uma inconsistência neste sistema. É notório de todos os usuários de smartphones que carregadores genéricos, de baixa qualidade ou clandestinos diminuem a vida útil do smartphone; portanto, se o usuário recorrer a essa opção, estará prejudicando seu próprio smartphone e incentivando um mercado eletrônico de qualidade duvidosa. Esta ilustração pretende expor que nossa proposta não impede ações tendenciosas antiéticas, imorais ou ingênuas. Propõe um ativo de conhecimento compartilhável que facilita uma auditoria de referência ética para um cenário.

Tendo exposto as características principiológicas contextuais que norteiam a engenharia inicial desta proposta, usaremos uma análise de tomada de decisão aplicada como uma entrada para a demonstração de operacionalização.

\subsection{Operacionalização em caso real}

A Figura 2 mostra um caso de tomada de decisão em [Glover 2017], "Acesso de adolescentes aos portais de pacientes". O modelo está disponível online por legibilidade 5 .

\footnotetext{
${ }^{5}$ https://cutt.ly/xzAMa6S. Disponível em 05/05/2021
} 


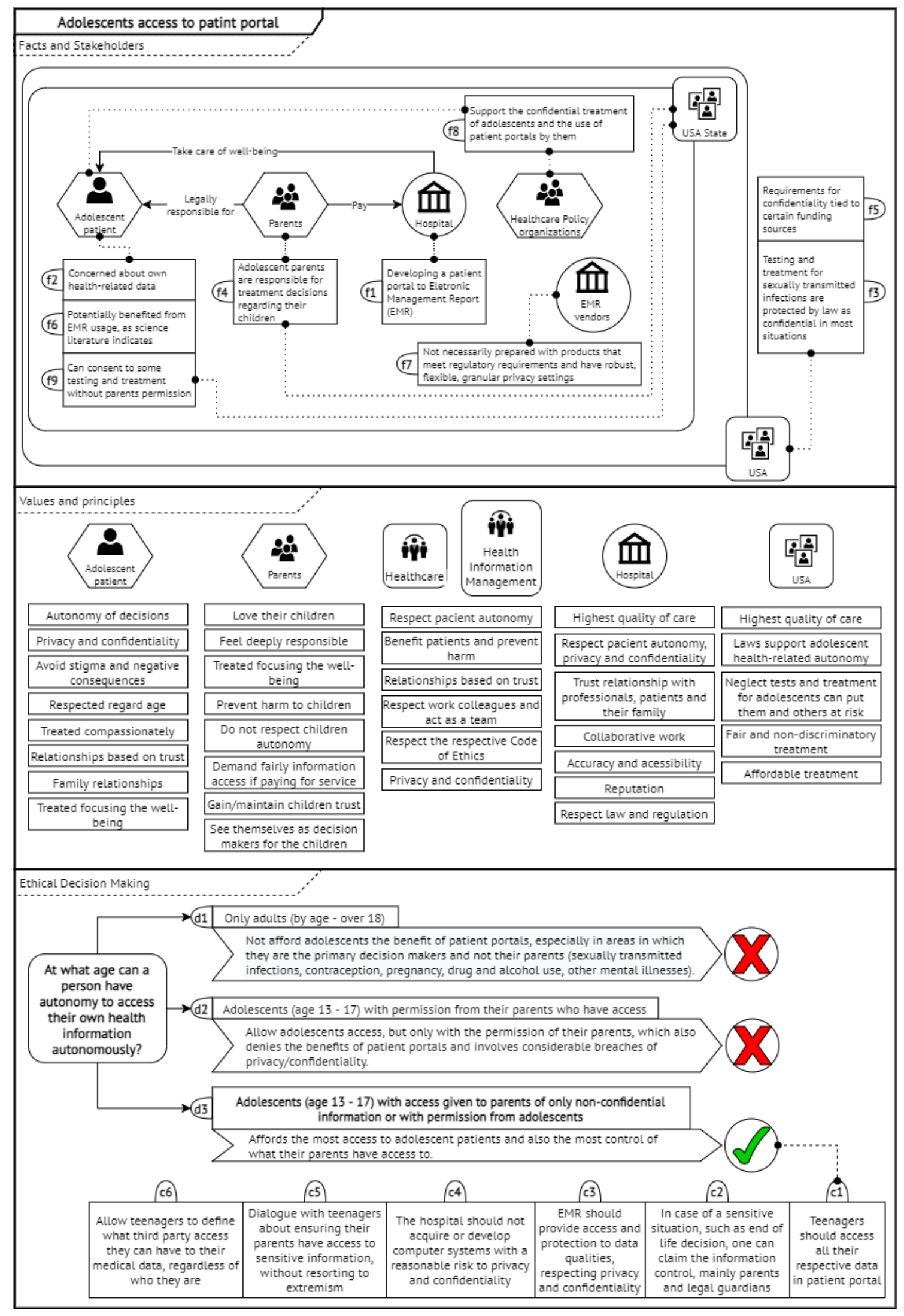

Figura 2. Acesso de adolescentes a portais de pacientes [Glover 2017], caso modelado 
A análise é baseada principalmente em três princípios éticos também expostos em [Glover 2017], Ética baseada em Virtudes, Princípios e Direitos. O modelo, então, deve representar princípios, direitos e virtudes. Não adicionamos informações, respeitamos fielmente o conteúdo e adaptamos apenas trechos, sem alterar a proposta central.

Antecipamos certas tensões críticas de antemão, que diferenciam a exposição em [Glover 2017] à nossa proposta: (i) por Transparência, fatos e dados usados nas análises devem ter fontes confiáveis, rastreáveis, exatas e objetivas, i.e., "alguns testes e tratamento" ou "certos estados" prejudicam uma avaliação ética; (ii) não há consequências, i.e., quais são as consequências de permitir que os adolescentes tenham poder de acesso aos seus dados pessoais? Neste caso, sintetizamos "justificativas" e "prevenções" como consequências, análise preditiva; (iii) existe certa inconsistência e descontinuidade entre os atores apresentados na análise, alguns que aparecem nos fatos não aparecem como partes interessadas e vice-versa, se os fatos os envolvem por que não são partes interessadas?

As três seções do modelo são autoexplicativas. Os atores envolvidos são apontados e representados pela combinação de contêineres e ícones. O hexágono indica um indivíduo ou grupo de indivíduos; o círculo, pessoas jurídicas, terceiro setor ou organizações específicas; o retângulo com as bordas arredondadas indica uma entidade simbólica, como "governo", "mercado" ou algum elemento abstrato. A Figura 3 indica o significado de cada elemento notacional. Os rótulos que começam com f são fatos; com d são decisões; e c são consequências.

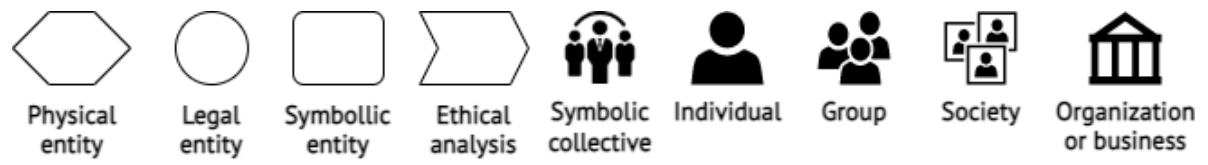

Figura 3. Elementos notacionais utilizados

Por se tratar de uma análise baseada em virtudes, direitos e princípios, a segunda seção é inteiramente dedicada à exposição dessas informações, onde podemos ver itens concordantes, neutros ou conflitantes. Por exemplo, enquanto os pacientes adolescentes valorizam a autonomia, os pais não; algumas leis e regulamentos garantem a autonomia dos adolescentes e do hospital e respeitam as leis e regulamentos; os funcionários valorizam a privacidade e a confidencialidade, assim como os pacientes adolescentes. Se o hospital prejudica a autonomia do adolescente, vai contra leis e regulamentos; se o hospital entende que as informações pessoais do adolescente estão acessíveis apenas aos seus respectivos responsáveis legais, implica implicitamente que o cenário é baseado no poder e no dinheiro, e não no bem-estar do adolescente.

\section{Conclusão}

Neste artigo apresentamos uma proposta preliminar de representação gráfica para EDMMs, inédita e inovadora, a ser desenvolvida com base na metodologia DSR. Construímos um protótipo para demonstrar a possibilidade de representar graficamente um caso real já analisado [Glover 2017]. Dispomos a ideia inicial e, como trabalho em desenvolvimento, esperamos complementá-la e incluir novos requisitos e recursos gráficos.

Conseguimos encontrar inconsistências e descontinuidades simples que são complexas na análise de um grande texto, como na análise de quatro páginas em 
[Glover 2017]; reduzimos as dimensões para apenas uma imagem de uma página. Como ponto negativo, representações gráficas estão sujeitas à interpretação semiótica notacional, ao contrário dos textos aos quais já estamos acostumados. Há novo aprendizado, para isso s visamos suavizar a curva de aprendizado propondo poucos elementos, simples.

Como valores de DSR [Wieringa 2014], esperamos a interação e colaboração da comunidade para desenvolver este artefato de uma forma útil para a tomada de decisão ética, com base em representações modeláveis computacionalmente. Como próximos passos, iremos analisar respostas para formalizar a proposta e aumentar seu desenvolvimento; analisar outros princípios éticos, possibilitando representações completas; aprofundar o potencial colaborativo da proposta, onde várias pessoas podem pensar-tomar decisões éticas coletivamente; formalizar uma notação consistente e sua lógica de design.

\section{Referências}

Baker, S. e Martinson, D. L. (2001). The tares test: Five principles for ethical persuasion. Journal of Mass Media Ethics, 16(2-3):148-175.

Barton, L. (2018). Adopt a black cat - here's how to make them look great on instagram. accessed: 03/03/2021.

Bioni, B. (2019). Proteção de Dados Pessoais A função e os limites do consentimento. GEN, Barueri, Brasil.

Buolamwini, J. e Gebru, T. (2018). Gender shades: Intersectional accuracy disparities in commercial gender classification. In Friedler, S. A. e Wilson, C., (eds), Proceedings of the 1st Conference on Fairness, Accountability and Transparency, volume 81, pp. 77-91, New York, NY, USA. PMLR.

Calma, J. (2020). Apple ditching chargers saves costs but not the planet. accessed: 03/03/2021.

Cottone, R. R. e Claus, R. E. (2000). Ethical decision-making models: A review of the literature. Journal of Counseling \& Development, 78(3):275-283.

Dascal, M. (2002). Language as a cognitive technology. International Journal of Cognition and Technology, 1(1):35-61.

Escobar, A. (2018). Designs for the Pluriverse Radical Interdependence, Autonomy, and the Making of Worlds. Duke University Press, Durham, USA.

Fieser, J. (2020). Ethics. In The Internet encyclopedia of philosophy.

Fung, B. (2021). Facebook bans trump from posting for remainder of his term in office. accessed: 03/03/2021.

Genon, N., Heymans, P., e Amyot, D. (2011). Analysing the cognitive effectiveness of the bpmn 2.0 visual notation. In Malloy, B., Staab, S., e van den Brand, M., (eds), Software Language Engineering, pp. 377-396, Berlin, Heidelberg. Springer.

Glover, J. J. (2017). Ethical health informatics: Challenges and opportunities. In Harman, L. B. e Cornelius, F., (eds), Ethical Health Informatics: Challenges and Opportunities, chapter 2, pp. 51-74. Jones \& Bartlett Learning, $3^{\text {a }}$ edição.

Johnson, D. (2008). Computer Ethics. Pearson, $4^{\mathrm{a}}$ edição. 
Jones, T. (1991). Ethical decision making by individuals in organizations: An issuecontingent model. Academy of Management Review, 16:366-395.

Kemp, S. (2020). Digital 2020: Global digital overview. accessed: 03/03/2021.

Laudon, K. e Laudon, J. (2020). Management Information Systems: Managing the Digital Firm. Pearson, New York, NY, $16^{a}$ edição.

Lewis, S. (2019). The racial bias built into photography. accessed: 03/03/2021.

Luca Casali, G. e Perano, M. (2020). Forty years of research on factors influencing ethical decision making: Establishing a future research agenda. Journal of Bus. Res.

Moody, D. (2009). The "physics" of notations: Toward a scientific basis for constructing visual notations in software engineering. IEEE Tran. on Soft. Eng., 35(6):756-779.

Nonaka, I., Nishihara, A. H., e Kawada, H. (2018). Knowledge-Based Management Theory, pp. 1-21. Springer International Publishing, Cham.

Rulli, T. (2017). For dog's sake, adopt! In Overall, C., (ed), Pets and People: The Ethics of Companion Animals, pp. 172-186. Oxford University Press.

Santoro, F. M. e Costa, R. M. (2020). A process to analyze ethical issues of information systems. In Anais do I Workshop sobre as Implicações da Computação na Sociedade, pp. 25-36, Porto Alegre, RS, Brasil. SBC.

Silva, T. (2020). Comunidades, algoritmos e ativismos digitais: Olhares afrodiaspóricos. LiteraRUA, São Paulo, SP.

Simon, H. A. (1979). Rational decision making in business organizations. The American Economic Review, 69(4):493-513.

Stair, R. M. e Reynolds, G. W. (2018). Principles of Information Systems. CENGAGE Learning, Boston, MA, $13^{\mathrm{a}}$ edição.

Tagiaroli, G. (2021). Tratecov: sistema do governo que sugere cloroquina não explica uso de dados. accessed: 03/03/2021.

Torres, M. (1998). Ethical decision-making models. accessed: 03/03/2021.

Tversky, B. (2001). Spatial schemas in depictions. In SPATIAL SCHEMAS AND ABSTRACT THOUGHT, pp. 79-111. MIT Press.

von Engelhardt, Y., Janssen, T. M. V., e Scha, R. J. H. (1996). The visual grammar of information graphics. In Proceedings Workshop on Visual Representation, Reasoning and Interaction in Design, pp. 1-11. AID'96.

Webb, D. (2021). How to upload high quality photos to instagram. accessed: 03/03/2021.

Whittier, N., Williams, S., e Dewett, T. (2006). Evaluating ethical decision-making models: a review and application. Society and Business Review, 1(3):235-247.

Wieringa, R. J. (2014). Design science methodology: For information systems and software engineering. Springer-Verlag Berlin Heidelberg, London, UK. 